\title{
The Vertigo of the Single Image: From the Classic Narrative "Glitch" to the Post-Cinematic Adaptations of Paintings ${ }^{1}$
}

\author{
Ágnes Pethő \\ Sapientia Hungarian University of Transylvania (Cluj-Napoca, Romania) \\ E-mail: petho.agnes@gmail.com
}

\begin{abstract}
As a possible cross section of cinematic narratology and the theory of intermediality the following essay assesses some of the effects of foregrounding the single, intermedial image within film. Specific figurations of intermediality that are experienced via the consciousness of single images, or some kind of "imageness" (i.e. as "intermedial references") are presented as well as the modes in which they can interact with the narrative structure of a film. This interaction ranges from a momentary interference with the narrative structure of a film to disrupting it altogether; it may consist in constituting the gravity centre of a plot, or even in becoming the "canvas" for a palimpsest of narrative modes and narratives.
\end{abstract}

Keywords: narrativity, intermediality, painting and tableau vivant in film, post-cinema, Lech Majewski.

\section{Introduction: Image versus Narrative and the Thresholds of Media}

The theory of intermediality in film has so far concentrated either on fundamental issues of the relations between cinema and the other media (i.e. on how these relations can be perceived, interpreted or categorized), or on identifying figurations of intermediality, and very little attention has been paid to the way certain figurations interact with the narrative context they appear in,

1 The article was written for the First International Meeting on Narratology and the Arts: "Art as Text. Narratological, Semiotic and Transmedial Approaches" that took place in Paris, December 7-8, 2012. Participation at this conference and the research for the article was partly supported by a grant offered by the Scientific Research Department of the Sapientia University, the Institute of Research Programs. 
or to the relationship between intermediality and cinematic narrativity in general. ${ }^{2}$ In recent years narratology has begun to foray into unchartered territories of inter-art relationships through its pursuit of transmedial concepts and models, and although the idea of transmediality relies on transmutability instead of the emphasis on media differences, on the whole, the search for a transmedial definition of narrativity has also, implicitly, launched the challenge to question the relationship between narrativity and medium specificity, or to explore even more specific connections between narrativity and intermediality. Marie-Laure Ryan concludes her essay On the Theoretical Foundations of Transmedial Narratology with these words that point in this direction: "the diversity of games that narrative can play with the resources of its medium is one of the many reasons that make the intersection of narratology and media studies, an area still largely unexplored, into a productive field of investigation." $(2005,21$.) The challenge for cinema is especially intriguing, as in the case of cinema, these "games that narrative can play with the resources of its medium" are even more relevant due to the particular relationship in a film between the unfolding narrative and what constitutes its specific medium: the moving image. So much so in fact that we might even say that there is a continuous "tug of war" between "image" and "narrative," a "tug of war" that is subordinated to the "negotiation" between information received via what happens/or what is told, and via what is shown or implied by single images.

Christian Metz's description of this relationship can be used as a first stepping stone in expanding on this idea here. In his book Film Language. A Semiotics of the Cinema he writes the following: "The rule of the 'story' is so powerful that the image, which is said to be the major constituent of film, vanishes behind the plot it has woven [...], so that the cinema is only in theory the art of images. Film, which by nature one would think adapted to a transversal reading, through the leisurely investigation of the visual content of each shot, becomes almost immediately the subject of a longitudinal reading, which is precipitous, 'anxious,' and concerned only with 'what's next.' The sequence does not string the individual shots; it suppresses them." (Metz 1991, 45-6, emphasis mine, Á. P.) The same idea is highlighted by André Gaudreault's metaphor, who claims that "cinema is a machine doomed to tell stories" $(1997,171)$. And we know that this "machine" found its ideal form in the classical Hollywood narrative film which laid down the ground rules for the so called "canonic story" promoted by various popular genres and by screenwriting manuals up to the

2 A notable exception in this respect is the volume Intermediality and Storytelling (2010) edited by Marie-Laure Ryan and Marina Grishakova which features several articles dealing with motion pictures. 
present. ${ }^{3}$ The classical Hollywood narrative film - as Bordwell $(1985,162)$ explains - consisted of storytelling techniques and patterns of visual composition that directed the viewer's attention not towards the contemplation of the pictorial qualities of the image but towards the comprehension of the plot and the understanding of coherent cause and effect, as well as time and space relations in film. This so called "self-effacing" style and the "narrative pressure" acting against the perception of singular images has been amply discussed in film theory. ${ }^{4}$

Its counterpart can be identified in what Tom Gunning described in a famously ground-breaking article as the "cinema of attractions" (1990). According to Gunning early film can be defined not as a form of storytelling but as a spectacle primarily focused on the "harnessing of visibility," on the sensation of "visual surprise." As Gunning admits "the transformation of filmic discourse [... that later] bound cinematic signifiers to the narration of stories and the creation of a self-enclosed diegetic universe" $(1990,60)$, i.e. the process that subordinated the "showing" to the "telling," can easily be seen as an inherent rivalry, "as a Cain and Abel story, with narrative strangling the nascent possibilities of a young iconoclastic form of entertainment" $(1990,60) .^{5}$ Nevertheless, this opposition can only be posited with a considerable degree of simplification, the "tug of war" oscillation between foregrounding the image and foregrounding the narrative in a fiction film, never results in the total surrender of one or the other. Stunning visual compositions often constitute "attractive" moments within the well oiled narrative structure or "transparent" imagery of classical genre films as well, ${ }^{6}$ and often even films with so called "minimalist" narration unfolding against a rich, visual style, bring into play imaginary narratives or narrative expectations to a degree that they can be seen not so much as defective but as deconstructed, or simply open ended narratives. ${ }^{7}$

Allowing for a more nuanced view upon the interrelationship of image and storytelling, and employing a psychoanalytic framework, in a much-anthologized

3 The fundamental elements of this "canonic story" that Bordwell describes in his book Narration in the Fiction Film (1985) correspond to the features identified by Marie-Laure Ryan in what she calls the "cognitive template constitutive of narrative" in its most general, transmedial sense (2005, 4-5).

$4 \quad$ For a recent view on the subject see Verstraten's analysis (2009).

5 Hence, extending the term, recent new trends that again place the emphasis on the sheer visual experience of the image are considered as some kind of return to this pre-narrative paradigm in the form of the "cinema of attractions reloaded" (Strauven, 2006).

6 For examples of this see several essays in the volume The Cinema of Attractions Reloaded (2006).

7 E.g. this is the case of the fragmented modernist narratives of Michelangelo Antonioni and his followers. 
essay on "visual pleasure in narrative cinema," Laura Mulvey has analysed the way the image of women in classical Hollywood movies arrests the flow of the narrative and how classical narratives deal with such moments, and stated that: "The presence of woman is an indispensable element of spectacle in normal narrative film, yet her visual presence tends to work against the development of a story line, to freeze the flow of action in moments of erotic contemplation. This alien presence then has to be integrated into cohesion with the narrative." (1975, 11, emphasis mine, Á. P.) Feminist and Freudian interpretations of the gaze aside, this is true not only for the image of the objectified or aestheticized woman in the heyday of Hollywood genre films, but for any "attractive" single image in the cinema, as well. In a later book entitled Death $24 \times$ a Second. Stillness and the Moving Image (2006) Mulvey herself considers cases in which moments of stillness break the flow of moving images, and - using Raymond Bellour's term create a "pensive spectator" who can not only "experience the kind of reverie that Barthes associated with the photograph alone, but this reverie reaches out to the nature of cinema itself. This pause for the spectator, usually "hurried" by the movement of both film and narrative, opens a space for consciousness of the still frame within the moving image," ${ }^{8}$ something that is "usually concealed by the film's movement, [and] its particularly strong inscription of the index" (Mulvey 2006, 186).

Focusing on the sheer visual pleasure of stillness means becoming conscious of the single image in cinema and experiencing its double release from: a) being inscribed within and subsumed by the narrative flow, and b) from experiencing it primarily as an index of a pro-filmic reality, thus experiencing its "imageness" as something more opaque. And whenever the image "closes up" upon itself in this way, at the same time it may also "open up" towards illusory inter-media and inter-art "transgressions"9 becoming more like a single photograph or a painting. We can see an eloquent example of this in the case of certain sequences focused on the portrait of Marlene Dietrich in Josef von Sternberg's films (see in Fig. 1 images from the prolonged close up from the Shanghai Express, 1932, a close up that has become one of the most often reproduced photographs of Marlene Dietrich). Or we may experience a similar phenomenon in modern cinema where still compositions often consciously

8 Pausing the image with the use of new technologies may have a similar effect, i.e. may "bring to the cinema the resonance of the still photograph" (Mulvey 2006, 186).

9 I have discussed the relationship between "opaque" imageness and illusory inter-art transgression of the image from a different angle in Chapter Three of my book (Cinema and Intermediality. The Passion for the In-Between), entitled The World as a Media Maze: Sensual and Structural Gateways of Intermediality in the Cinematic Image (Pethő 2011, 95-179). 
break down the barriers between cinema and the other visual arts, and are often saturated with symbolism. ${ }^{10}$ The playful tableau vivant scene from the classic musical directed by Charles Walters, The Easter Parade (1948) makes this process self-reflexively explicit. [Fig. 2.] Here we see both the way a woman is treated like a picture and how such an arrested image becomes a threshold between cinema and graphic arts. First we have a trompe l'oeil setting involving a motionless model and a painting, where initially we confuse the living model with a picture as the widening of the frame reveals that the model is in fact doubled by another woman who looks exactly like her and who is sitting in front of a glass pane framed like a canvas opposite the painter. The ladies are easily stepping from one picture frame, from one medium to another, and the trompe l'oeil perception of women and pictures, of cinema and painting is then repeated in the subsequent shots in which a series of picturesque women are paraded posing as hybrid cinematic tableaux vivants, mixed photo-painting "illustrations" of a magazine.

Thus intermediality and non-narrativity, or halting the narrative are usually strongly bound together ${ }^{11}$ even if this is not an exclusive bond on either part. In general, it is prudent to affirm that whenever some kind of a break in the seamless "welding" of image (or any other media) and narrative becomes perceptible (as the medium moves to the foreground pushing the narrative to a less perceptible level), the possibility for intermediality arises, or vice versa, figures of intermediality can render the text less transparent towards the unfolding of a story. (E.g. foregrounding single images by repetition may introduce musical structures within a film, or an overflow of verbal or written language may infuse a sense of literariness, and so on.) Here we can also remember that Joachim Paech has compared the experience of intermediality itself to the perception of the duality of "figure" and "ground" as it is understood in the visual psychology of the so called Gestalt theory. As he described it: "the medium formulates and the form figurates," i.e. the medium becomes observable as form, and the form serves as a medium for the figure that is then re-inscribed within the form of another medium. ${ }^{12}$

Bearing in mind that according to this view intermediality is understood as the trace of the other medium within a medium and it is always describable as

10 A case in point for this can be Antonioni's famous closing shot of L'Avventura (1960).

11 We may also note that pre-narrativity is also strongly bound to intermediality in cinema, as Gaudreault explains in his chapter on "early cinema's intermedial meshing," in the beginning cinema was so intermedial that it "was not even cinema" $(2009,156)$.

12 See more on this in Pethő $(2011,40)$. 
such through the figures of such an inscription, ${ }^{13}$ I propose to outline as a possible slice of a narratological perspective over intermediality within film some of the modes in which specific figurations of intermediality can interact with the narrative structure of a film, instances of intermediality that are experienced somehow via the consciousness of single images, or some kind of "imageness." ${ }^{14}$ As a further delimitation I propose to present only instances that can be fitted in the category of "intermedial reference" in its narrow sense, ${ }^{15}$ referring in this case to what is known in German as "Einzelreferenz," i.e. "individual reference," (as opposed to Systemreferenz/"system reference"), meaning for example either a direct "quotation" or insertion of a painting, or other work of art, or media representation in a film that gains some emphasis at a given moment in the film. These references can be operational either within the bounds of a realistic representation as elements of the pro-filmic and the diegetic world, or they can be viewed within a self-reflexive frame of interpretation as figurations of intermediality. As such, their role can vary from a momentary interference with the narrative structure of a film to disrupting it altogether; it may also consist in constituting the gravity centre of a plot, or in becoming the "canvas" for a palimpsest of narratives.

\section{From Narrative "Glitch" to Displacement and Extreme Fragmentation}

As any other extra-textual allusion, an intermedial reference, e.g. a painting appearing amidst the cinematic images, can have the effect of de-linearizing narratives. Just like the petrifying gaze of Medusa that W. J. T. Mitchell

13 Paech describes this "as a figured process or a specific configuration in the film" (2000).

14 I am quite aware of the fact that this constitutes a vast area of possible investigations, so what follows can in no way be a comprehensive overview of these issues, the article merely attempts to direct the attention to the interaction between figurations of intermediality and narrativity in film by pointing to areas and phenomena where this can be relevant.

15 Both Irina O. Rajewsky (2005) and Werner Wolf (2002) use it more broadly, both in the sense of individual and system reference. See Rajewsky's definition of intermedial references as "meaning-constitutional strategies that contribute to the media product's overall signification: the media product uses its own mediaspecific means, either to refer to a specific, individual work product in another medium [...], or to refer to a specific medial subsystem (such as a certain film genre) or to another medium qua system [...]. The given product thus constitutes itself partly or wholly in relation to the work, system, or subsystem to which it refers." (Rajewsky 2005, 52-53.) 
described with regards to ekphrastic literature, where pictures can threaten to silence the poet's voice and fixate the observer's eye ${ }^{16}$ in the case of cinema, inserts of paintings or still images may introduce minor halts in the narrative either in the form of narrative blind spots, "glitches" or puzzling diversions. Belén Vidal compares the effect of "the interruption that the tableau brings about when inserted in the moving-image medium" to Lyotard's interpretation of anamorphosis in the famous Holbein painting, The Ambassadors (1533) [Fig. 3.], saying that: "the superimposition of a different mode of representation over the "realist" frame (requiring the eye to move and therefore to see) exposes the differential movement of the film-work, where narrative represses it" (Vidal 2012a, 120).

The idea is reinforced by Stephen Heath's analysis (1986) of the disruptive effect of a cubist painting in Hitchcock's Suspicion (1941) [Fig. 4.] as an unexpected, unexplained incident appearing as a momentary "glitch" in the narrative. Hitchcock, in fact, uses paintings or painterly compositions quite often to rupture the seamless fabric of his narratives. ${ }^{17}$ Compared to the realist space of the narrative, the painting in his films can appear as an "opening" towards another level of existence: an abstract "space" onto which Hitchcock often displaces the horrifying experience of crime, fear or, in many cases, desire, bordering on perversion (e.g. Vertigo, 1958). The flow of the narrative denouement usually subsumes this strange image wedged into the cinematic space, nevertheless, the painting acts like a possible double - "a dangerous other" (to apply Mitchell's term) - for the cinematic image, hovering over the enthralling tale, ready at any time to take charge, threatening to disrupt the reasonable (and discursive/narrative) order of the world and to invade it with abstract shapes and lines, with images that resist to "tell" and impress the viewer with what they "show:" with their spellbinding visual presence. In this we can also see a displacement from "single reference" (the insertion of a painting) to "system reference" (as the moving image itself assumes the characteristics of a painting through specific techniques of lighting, framing and mise-en-scène). ${ }^{18}$

16 According to Mitchell "Medusa is the perfect prototype for the image as a dangerous female other who threatens to silence the poet's voice and fixate his observing eye" (1994, 172).

17 I have analysed this in detail in a chapter of Cinema and Intermediality entitled Spellbound by Images: The Allure of Painting in the Cinema of Alfred Hitchcock (Pethő 2011, 179-231).

18 It has to be noted that "system references" (i.e. the cinematic image becoming like a painting) can be achieved without "individual references" to particular paintings, and can also vary from a limited "reference" (the painterly style of a particular artist) - as we see in many cases in modern cinema (e.g. the shots resembling De 
On the other extreme we have Jean-Luc Godard's cinema, where for example, the multiple instances of the unexpected inserts of paintings - a case in point: the unusually fragmented narrative of Pierrot le fou (1965), in which all kinds of pictures pop up without any dramatic motivation ${ }^{19}$ - not only induce a puzzling fragmentation into the narrative, and divert our attention from the story by the visual surprise, but can ultimately provide a lyrical and musical structure built on variations and repetitions. His latest work, Film Socialism (2010), described by its subtitle as "a symphony in three movements," offers a mélange of photo-filmic experiences "texturized" by the collage of quotations from other films and the presence of pictures within pictures, and also by the "modulation" of the cinematic image itself, while the break between image and narrative appears not as a consequence of the emergence of "imageness" as a figure but as a constant doubling, where fragments of narratives, verbal reflections flow together with the various kinds of images, but are not necessarily connected to the images.

\section{The Picture as an Enigma, or Narrative as a Prolonged Caption to a Tableau}

Paintings becoming more than props in a setting for a narrative always bring an excess of signification to cinematic representation that is not easily defined. Paintings in cinema always cast a certain "aura" around their referent, and they are always "attractions" capable of becoming imprints of the entanglement of great emotions. No wonder that film noir narratives are full of paintings (often portraits of their emblematic character, the femme fatale), and alluring, painterly compositions accompanying unexpected plot twists, and over-boiling tensions. According to Thomas Elsaesser (2002) a painting in a film signifies at the same time both too much (seen in the context of the history of art) and too little (merely another image, amidst the many others that make up a film). He also considers that "a painting in a film often creates a gap which the narrative has to motivate," and this gap can be filled either by the presentation of an artist

Chirico, Rothko or Pollock in Antonioni’s films) - to a more "generic" reference (i.e. being "like a painting" in a more general sense), as we see in the fragmented imagery of Serghei Paradjanov's highly ornamental cinema, where images become like paintings not by reference/resemblance but because of their static framing and mise-en-scène, and the singular sensual presence of objects and haptic textures (see Tarnay, 2003).

19 And even if we may find some elements in the image or the voice over narration that seem to connect the paintings to the moving images, the sudden change of medium is always perceived as a disruption of the cinematic sequence. 
as the protagonist, or "by pointing to it as the source of an enigma - the enigma attaching itself not so much to who is being represented as to why the represented is an enigma to one or several of the characters." Or, to quote Belén Vidal who analyses the role of portrait paintings within film from several vantage points in her book on figurations of the period film genre, Figuring the Past: "the tableau in film is in itself an a-narrative figure which may, however, work its way into the fiction as metaphor, a secret: a representation that hides another. As Bonitzer points out, '[as] parody, homage or enigma, the shottableau always provokes a splitting of vision and gives the image the quality of a mystery, whether in the religious or in the detective-story sense." (Vidal 2012a, 120.) It is as if a painted picture in a film invariably activates what Roland Barthes called the narrative's "hermeneutic code," ${ }^{20}$ but we might also say - Elsaesser adds - that it activates one of Todorov's properties of the fantastic, a hovering, a consistent undecidability of discourses." In films like Otto Preminger's Laura (1944), Fritz Lang's The Woman in the Window (1944), Jacques Tourneur's Experiment Perilous (1944), Hitchcock's Rebecca (1940) or Vertigo (1958), and several others from the film noir canon, narrative often unfolds as a step-by-step clarification of an enigma embodied in a painting. [Fig. 5.]

And while the paintings that appear in such films are hardly ever of much artistic value being more often than not kitsch portraits that infuse the picture with a touch of mannerism that goes well with the melodramatic genre they appear in, they are highly effective both in focalizing the emotional charges of the story, sustaining the suspense as a riddle, and in acting as a tangible form of an enigmatic content that can be only painstakingly and never fully elucidated. As even when the detective story reaches its closure, such stories invariably attest to the persistence of the myth of the inscrutable nature of femininity, something that is both flaunted and forever enfolded by the painting of a woman. At the same time, these paintings are also working essentially on an intermedial level by exhibiting a perpetual confrontation between the representational modes of cinema and painting, pointing either - as Elsaesser suggests - to the superiority of the moving picture over the expressly "bad painting" by "warming itself at the ashes of a pictorial form the cinema helped

20 In $S / Z$ (1974), a detailed analysis of Balzac's short story Sarrasine, published in 1970, Roland Barthes developed a concept that every narrative is interwoven with five codes that drive the reader to maintain interest in a story. The "hermeneutic code" refers to any element in a story that is not explained and, therefore, exists as an enigma for the reader that demands clarification. Most stories hold back details in order to keep the audience guessing while the reading progresses and finally all loose ends are tied off. 
to consume" (2002), or reversely, to the superiority of the painting by foregrounding the limits of its mechanically reproductive nature. In modernist art cinema the mannerism induced by the kitschy portrait disappears, and while the basic function of the picture as a riddle within the narrative is preserved, its media reflexive potential building on the tension between the two art forms is much more emphatic and sophisticated. ${ }^{21}$

On the other hand, the excess of signification sensed in a painting that is introduced in a film can not only make it like a sphinx that guards a mystery, but can sometimes make the painting be conceived literally as a "representation that hides another." A picture that, according to popular belief, is always "worth a thousand words," can be used as a representation to encrypt a narrative, to hide a story, a story that needs to be unearthed and deciphered through the plot. Thus we have film narratives feeding on the sheer excitement of a yarn being unravelled from the "a-narrative" excess of visual representation, and present paintings as fossilized stories that preserve fragments of private and public history. One such film is The Vanishing Point (Ce que mes yeux ont vu: Le Mystère Watteau, 2007) directed by Laurent de Bartillat, in which finding the presumed love story of Watteau and his muse hidden by a painting is shown in parallel with (and allegorized by) the uncovering of a picture within a picture, and a painting underneath a painting, and in which the thrill of detecting the story itself, of exploring, scanning the minute details of a painting, of getting immersed into the visual world of a painter equals the excitements of a detective story. ${ }^{22}$ [Fig. 6.] Bartillat's film is

21 Belén Vidal's examples discussing this function of the paintings eloquently demonstrate this. She quotes Jarman's reworking of the biopic in Caravaggio (1986) where "the tableau vivant explores the mutual contamination of the sacred and the profane against the background of the sixteenth-century politics of art and patronage,” or Peter Greenaway's The Draughtsman's Contract (1982), “where the double-framed vedutas of the aristocratic country estate are presented as clues to the murder mystery that structures the film" (2012a, 120), and examines the way in which the insert of a shot-tableau reproducing the lighting and composition of the canvas The Nightmare, by J. H. Füssli in Eric Rohmer's The Marquise of O (1976) "works as a call in the text - the figure as intertextual moment that evokes previous representations of the feminine body in Western art. But the frame also does something else: it flags up the materiality of the female body - its very presence - as the absence that determines the enigma of the film. The shot-tableau of the Marquise thus becomes the 'stain' at the centre of a text that displaces attention from predatory male sexuality to the enigma of feminine sexuality as both scandalous and non-representable" (Vidal 2012a, 121). For more in-depth studies of paintings used in this way see: Dalle Vacche (1996), Felleman (2006).

22 The way information is extracted from the pictures is not far from clichés of detection employed by crime and spy narratives, where we have clues hidden in images (like in The Da Vinci Code, 2006) or entire messages encoded within pixels of digital photographs. 
also a good example of a narrative in which the excess in signification identified in a painting unfolds by way of reframing art (or history) as private history. We have the same pattern in the Girl with a Pearl Earring (Peter Webber, 2003), Volavérunt: The Naked Maja (1999) by Bigas Luna, or in Peter Greenaway's Nightwatching (2007). In each of these cases the film offers a narrative contextualization to a single tableau. [Fig. 7.] Belén Vidal (2012b) identified such a reframing as a key figure in historical biopics which often construct their stories as a kind of "psycho-ekprasis" "around a fetish-tableau" that is shown either at the beginning or at the conclusion of the film (e.g. Elizabeth, 1999, Elizabeth, the Golden Age, 2007, or: The Queen, 2006). Vidal also points out that the relationship in such historical or "heritage films" between spectacle and narrative is thus inverted, as the story "becomes an elaborate caption around the fetish-tableau. [Fig. 8.] In The Private Lives of Henry VIII and The Madness of King George the tableau is introduced at the beginning of the film, almost as a mythical point of origin for these fictions that seek out the man behind the public image" (Vidal, 2012b, 42).

\section{The Generative Force of Images: Moving from Inspiration to Adaptation}

\subsection{Pictures as Paratexts and Pre-texts}

Genette defined paratexts as the "thresholds of interpretation," or quoting Philippe Lejeune, as "the fringe of the [printed] text which in reality controls one's whole reading [of the text]" $(1997,2)$. In cinema, sometimes, not texts but references to concrete paintings are used to introduce the film, paintings appearing as the background image upon which the opening credits unroll, or standing between the title and the body of the film itself. In such cases both the medial difference (the textural otherness) perceptible in the paintings, and the associations generated by the sight of the familiar paintings, defer the spectator from a too early immersion in the story, constituting an "obstacle" that has to be acknowledged and preserved in our minds, and as a "mirror" to which we suspect that we will need to return after having seen the whole film to look into once more in order to see the whole picture more clearly (thus, from the very beginning, such a device is also securing a markedly reflexive, non-linear "reading" of the film). Such images are always palpable "frames" first that wrap the story, and "thresholds of interpretation" second. And when it comes to interpretation, they often pose more questions than give answers, the heavy and enigmatic "texturality" of the painting folding onto and seeping into the 
cinematic images that follow, however, without its polysemy ever being diluted by the narrative.

Andrei Tarkovsky makes the viewer contemplate a detail of Leonardo da Vinci's unfinished and almost monochrome painting, The Adoration of the Magi as the camera glides slowly above the surface of the canvas at the beginning of The Sacrifice (1986), introducing not only key motifs of the film, but establishing a rapport with the cinematic image that is similar to religious icons one touches and beholds with reverence, a rapport that Tarkovsky often underscored in his films. Bernardo Bertolucci has three films that invite their spectators to step over the thresholds of paintings before being immersed in the diegetic world that opens up in the cinematic images. The Last Tango in Paris (1972) displays two paintings by Francis Bacon in the title sequence. These paintings are used as paratexts that set the mood for the story that will unfold in the film, pointing to a source of inspiration that generates the specific expectations that the film attempts to equal (this inspiration is later reinforced in this case by the resemblance in the portrayal of the protagonist to the portrait of Bacon himself). [Fig. 9.] Similarly, Novecento (1976) begins with the reproduction of Giuseppe Pellizza da Volpedo's painting, the Fourth Estate (Quarto Stato, 1901) and thus foreshadows not only its ideological content but also a narrative moulded as a series of loosely connected (historical) tableaux. The Spider's Stratagem (1970), an adaptation of a metafictional detective story by Jorge Luis Borges (The Theme of the Traitor and the Hero), begins with the enigmatical animal symbolism of the naïve paintings of Antonio Ligabue (and reinforces the undecidability between subjective and objective viewpoints through paraphrases of Magritte and De Chirico later on in the film).

We can also distinguish an even further step in the use of paintings in this respect, when we have a minimalist narrative (or a narrative fragment) that is entirely conjured up by associations to single pictures as their pre-texts. This latter form, however, is prevalent not so much in fiction films, but in video installations or experimental short films characteristic of the so called postcinematic age. We may list here such experiments as Eve Sussman's transmedialization of Las Meninas, entitled 89 Seconds at Alcázar (2004), [Fig. 10.] a high-definition video installation expanding the world of the Velázquez masterpiece into a string of images among which the one seen in the original painting is merely the imprint of 89 seconds (maybe questioning its status of a pregnant moment) within a world in perpetual motion, or Bill Viola's several video art projects inspired by famous paintings, like The Greeting (1995) based on the Visitation (1528-29) by the Italian artist Pontormo. Although such projects are usually interpreted from the point of view of their relationship to temporality (as the figures of the painting originally conceived in relations of 
surface, space, composition are reconceived in an architectural setting, subordinated to changes in time ${ }^{23}$ ), and from the point of view of the interplay between classic iconography and contemporary screen culture, dwelling on the way in which - as Agamben $(2011,61)$ put it - "under the incredulous eyes of the spectator, the musée imaginaire becomes the musée cinématographique," evaluating them from the perspective of narrativity is perhaps equally relevant. Transforming the motionless picture into a slowly moving sequence of images in a way always, paradoxically, "narrativizes" the non-narrative, the descriptive qualities of paintings, unfolding before our eyes minute details (and changes) of a fictional world inhabited by characters, and foregrounding a density in gestures, sensations, and emotions. At the same time, the trans-medialization also "secularizes" the revered artwork as the painting transmutes into the more common realm of moving images and the minimalist narrative frame of everyday actions and gestures. However, this is an ambivalent process: by magnifying simple gestures and investing them with the tension of cinematic narrative expectations while preserving the reference to the painting, the image, dislocated from its original frame (and stripped of its original "fine art" aura), does not really lose one status and gains another, but becomes suspended in the "in-between" of cinema and painting. ${ }^{24}$ Such post-cinematic projects always materialize on the sensual thresholds between "cinematic" movement and the still image, and also, markedly, between narrativity and non-narrativity, as the images do commence to unfold a possible story, yet this is at the same time folded back, re-absorbed in the "texture" of the image itself (or maybe transmuted onto a more "molecular level” to use Deleuze's term, 2004): by the sensation of forms, colours, lights, shadows, fabrics, and bodies in movement.

Short films like Marcell Iványi's The Wind (1996) or Ballad (2005) can be placed somewhere in between full blown narrative adaptations of single images,

23 Tatiana Senkevitch (2012) examines 89 Seconds at Alcázar in relation to its prototype, Diego Velázquez's Las Meninas, and points out how Sussman's artistic technique, the staging of light, choreographed movement, sound, and gestures, in particular, dilate the image by amplifying the visual characteristics of the original Baroque painting.

24 Agamben's analysis of "inserting time in the images" dwells also on the effect of a newly (re)constituted aura of the image through the infusion of motion. He explains: "the spectator realizes with surprise that what caught his attention is not just the animation of images that he was used to considering immobile. It is, rather, a transformation that concerns the very nature of those images. When, in the end, the iconographic theme has been recomposed and the images seem to come to rest, they have actually charged themselves with time, almost to the point of exploding. Precisely this kairological saturation imbues them with a sort of tremor that constitutes their particular aura. Every instant, every image virtually anticipates its future development and remembers its former gestures" $(2011,61)$. 
and minimalist video installations. Moreover, these particular examples also use their intermedial references to representations taken from Western culture in a more complex interaction with their suggested narratives grounded in a specific East European historical context, thus implicitly also constituting examples not only of transmedial, but of trans-cultural narrativizations of pictures. In the former example the visual narrativization of a black and white photograph by the French photographer Lucien Hervé (Three Women, 1951) is achieved through imagery that connects both to a kind of "vernacular" iconography (images referring to specific Hungarian history filtered through the stylized "choreography" reminiscent of the films of Miklós Jancsó) and to a more universal, European film history (the same photo being paraphrased through a similar circular camera movement in Jean-Luc Godard's Weekend made in 1967). [Fig. 11.] Through this there is also another kind of metanarrative tension that is introduced into the film: reading of the implied "narrative" is continually oscillating between the levels of reading the universal symbolism of images, and decoding a more specific, "local" signification, where the origin of the images (Hervé's photograph) and the origin of the photograph (France, Audincourt) comes as a surprising surplus of information that frames and re-frames the film (with the title being shown at the beginning and the original photograph itself being shown at the very end). Iványi’s next similar project, Ballad (2005), which generates its images from the same Fourth Estate that Bertolucci used in Novecento, operates perhaps even more consciously with balancing in between the effects of closeness and familiarity on the one hand, and distantiating abstraction, on the other, only in another way: this time it is not the familiarity of local (film) history that attracts the viewer, but the spectator is literally drawn near to the surface of the image through the marked haptic quality of the spectacle, whereas the artificiality of the painted backgrounds reminiscent of Pellizza da Volpedo's painting (and thus perhaps even of Bertolucci's film) together with the use of a fictive language have an increased alienating effect.

\subsection{Painterly Stylization as (Authorial/Rhetorical) Metalepsis}

A painterly composition or distortion of the image can serve as the marker for metaleptic leaps between embedded and/or ontological levels of the narrative (e.g. the leap from reality to fiction/fantasy is often shown in narratives this way: we can remember in this respect the famous dream sequence that appears 
as a Dali painting in movement in Hitchcock's Spellbound). ${ }^{25}$ However, sometimes a painterly stylization that has its source in a well defined corpus of paintings (a limited "system reference") can also be interpreted as a "loop" between the subjectivity of the fictional character and the meta-discursive level of the author: ${ }^{26}$ signalling both the "authorial" constructedness of the visual narrative and a cinematic vision anchored in the consciousness of the character. ${ }^{27}$ This is the case for example in films about famous painters like Love is the Devil (John Maybury, 1998) presenting images from the life of Francis Bacon [Fig. 12.], or Caravaggio (Derek Jarman, 1986), that project stylistic features of their paintings onto the screen (colour scheme, lighting techniques in Jarman's film, skewed points of view, odd fragmentations of bodies, and image distortions in the film about Bacon, etc.) in scenes which do not necessarily reproduce actual paintings. ${ }^{28}$ However, this authorial metalepsis can also be considered of a more or less "rhetorical" type, because even if the stylization extends to several scenes, this stylized filter soon becomes "transparent" and the viewer can be immersed in the diegetic world, almost in the same unobstructed way as it is done in the case of any classic narrative film, and ultimately this "breach of illusion does not threaten the basic structure of the narrative universe" (Ryan 2006, 207).

\subsection{The Tableau Vivant from Hypotyposis to a Palimpsest of Narratives}

In its minimal form the tableau vivant can be similar to the literary trope of hypotyposis $^{29}$ adding a vivid, painterly quality to the otherwise transparent

25 See a more detailed presentation of the possibilities of intermediality as metalepsis in my analysis (Pethő 2010) of Agnès Varda's films from this point of view.

26 I am referring here to the author and not the "monstrator" because according to Gaudreault: "the monstrator [...] is a plural agent delegated to so many facets of the production that we cannot view it as a 'true focal consciousness' unlike the textual narrator" (2009, 72).

27 It is the element of intermedial reference that makes such a technique different from the type of "free indirect vision" that we have in modernist cinema's painterly images.

28 This can be seen as opposed to the genre of a more classical biopic where we have "normal" images, and compositions resembling the famous paintings are shown on the level of mise-en-scène, on the level of the profilmic "reality" awaiting the eye of the painter who sees them and transfers them on canvas (such scenes can be seen in Minnelli's 1956 film about Van Gogh, Lust for Life). Maybury's film on Bacon also inserts such a sequence in the scene that shows George Dyer's death in the manner reminiscent of Bacon's triptych with the same subject.

29 As a literary device the most relevant features of this trope can be summarized in this way: "hypotyposis paints things so vividly and with such energy that they become in some way visible, it also turns a narrative or description into an image, a picture, or even a living scene" (Dupriez 1991, 219-220). Similes, allegories can all function as hypotyposis when they "paint a picture." 
cinematic image, and providing a quick rhetorical metaleptic wink at the knowledgeable spectator. We can see such an instance in Albert Lewin's casual tableau vivant reproduction of Manet's Bar at the Folies-Bergère (1882) in The Private Affairs of Bel Ami (1947), where the protagonists are seen entering the bar. The moment when the actual tableau (almost) comes together is quickly swept away, and the characters all seem ignorant of walking through a cinematic paraphrase of a painting, but the effect of the insert can remind us of Barthes's description of the punctum in photography, "an accident that pricks" the spectator $(2010,27)$, a detail within the flow of moving images that can also expand for a moment, throw the single image into relief, and infuse the otherwise insignificant cinematic frame with a liveliness and a vibration that is not diegetic, that has nothing to do with dramatic tension, but seems to communicate directly with the viewer. As such it also functions as a rhetorical metalepsis, an aside. [Fig. 13.]

A similar example can be seen in Woody Allen's film, Midnight in Paris (2011), at the beginning of the film the long shot of the colourful park scene with the tiny characters at the bridge in the background not only resembles impressionist paintings in general but at some point the image recomposes ${ }^{30}$ one of Monet's many paintings of water lilies. The counter-shot of the same scene, the reversed camera angle focusing on the characters pushes the Monet image into the background and proceeds with the dialogue of the light-hearted romantic comedy. Woody Allen's shot/counter-shot sequence is like a didactic explanation of how the intermedial figure/ground, image/narrative dynamics can work in a film: first we see the intermedial figure (the paraphrase of Monet) coming to the foreground, then, as the characters come to the fore in a close up, the narrative suppresses it, and the figure is visible no more, the magical "accident," the touch of impressionism over the cinematic image fades away. Later a paraphrase of Van Gogh in the starlit sky behind the characters works much in the same way.

In other cases, however, the figure appears not just as a media reflexive trope - "a composite monster" as Pascal Bonitzer put it $(1985,31)$, or a deliberate troping of the hybrid nature of the cinematic medium (cf. Peucker 2002, 295) but also a trope with more complex narrative implications, despite being usually considered an a-narrative device. ${ }^{31}$ By contrasting stasis with motion, a tableau vivant can be used to counterpoint the flow of the narrative, and as

30 The Monet image emerges from the sequence of cinematic images much in the same way as we see the original painting being reconstituted by a movement that slowly fits the pieces together in Eve Sussman's 89 Seconds at Alcázar and Bill Viola's Greeting.

31 See the quotation from Belén Vidal earlier in this article. 
such, even to signal the inadequacy of narrative structures. Jean-Luc Godard's Passion (1982), for example, uses a cinematic re-enactment of a series of famous paintings exactly in this way, as a site where the palimpsest-like potential of the cinematic image emerges against conventional narrative expectations, offering a platform also for and an explicit critique of a Hollywood-style storytelling.

If a single painting wedged into the cinematic space works like anamorphosis, then a tableau vivant, in which a painting is transposed/adapted as a more or less static scene onto the screen, excels in its complexity comparable to a palimpsest. Moreover, such a tableau, as a highly saturated picture oscillating in-between the autonomous, individual image and the image subordinated to the narrative sequence, appears not only at the cross-section of several arts, but it can also always be perceived both as a palimpsest of different narrative modes (that of painting, cinema, theatre/opera, even literature when language is brought into play), as well as a palimpsest of narratives: where the "story" condensed into the painting (with its enigmatic characters), the "story" of the painting as an artwork (and all its known interpretations) collapse into the diegetic story unfolding in the film that incorporates it and feeds on it.

We have a whole encyclopaedia of the different variations of this trope in Lech Majewski's films. The work of the Polish director, who is also a renowned painter and writer, stands out in this respect not only because of the frequency he uses this trope but also because of the way he reconceives the tableau by exploiting its affective-performative and embodied aspects. The Roe's Room (1997) is recounting his own life story through tableaux compositions reminding us of famous paintings that appear literally as the sensuous present of the past, as living, breathing pictures painting an organic landscape of memory and artistic imagination. In The Garden of Earthly Delights (2004) we see a dying woman and her lover enacting (and recording with a small video camera) scenes from Bosch's eponymous painting - teeming with hybrid creatures transgressing their existence - in an attempt to rise above the imminence of death by using their own bodies as "living pictures" to create a sensual interface between art and life, where living the pictures and becoming the pictures themselves opens up the horizon towards a two-way transgression: of art pouring into life, and life entering into the heightened experience of the world of art.

Perhaps Majewski's most famous endeavour so far, The Mill and the Cross (2011) is a feature film length tableau vivant - a post-cinematic cross-breed between cinema and painting and installation art - that presents in a selfreflexive loop the creation of the painting by Brueghel within the "story" (or more precisely "stories") represented by the painting. At the end of the film this peculiar cinematic tableau is then wrapped up in an even further reflexive frame of the museum space (suggestive of an art historical narrative context) by 
the camera that slowly backs away from the moving image revealing the original Brueghel masterpiece hanging alongside other paintings in Vienna's Kunsthistorisches Museum. In the film the details of the painting itself are spread out into a succession of loosely connected cinematic scenes, individual vignettes focusing on the activities of the small figures seen at the foot of the Calvary. As the panorama unfolds into the individual scenes, the film also weaves together seamlessly the narrative modes of literary storytelling (with dialogues, monologues and comments), of theatrical re-enactment, character interaction and choreography of bodies in space, in addition to the density of narrative painting evoked through the picturesque cinematic images (digitally mixing painted backgrounds and photographic techniques imitating painting) that often display frames within frames acting as tableaux within the overall tableau. [Fig. 14.] And similarly to Majewski's earlier films, the hybrid, postcinematic moving image ${ }^{32}$ becomes in this way a unique platform for a fusion between the sublime artifice of painting, the tangibility of moving, bleeding, feeling bodies and the technical wonder of digital cinema, where the cinematic tableau vivant is actually performing the basic "narrative" of the image as a medium - just as Hans Belting (2005) describes - that of bodies caught in the process of becoming images, and images becoming bodies that we have to relate to in all kinds of situations and narratives.

Thus the tableau vivant - a privileged site for moving image experiments that go beyond traditional genres of cinema - can be seen as a self-reflexive trope potentially re-enacting the way images "come to life" in a narrative, and also, paradoxically, it appears both as a figure that sustains the resistance of the single image to being subsumed by the flow of cinematic narrative and a figuration that can offer the highest possible condensation of narrative modes that an inherently intermedial cinema can offer.

\section{References}

Agamben, Giorgio. 2011. Nymphs. In Releasing the Image. From Literature to New Media, eds. Jacques Khalip and Robert Mitchell, 60-83. Stanford: Stanford University Press.

32 The artist's personal website (http://www.lechmajewski.com/) defines the film as a "unique digital tapestry," and although The Mill and the Cross can be considered a theatrical movie, the film has often been shown in museum spaces around the world, and in 2011 Majewski also displayed parts of it as a moving image installation entitled Brueghel Suite both in the Louvre and in Venice (in the Chiesa di San Lio) as a part of the $54^{\text {th }}$ Biennale. 
Barthes, Roland. 1974 [1970]. S/Z. New York: Hill and Wang. Barthes, Roland. 2010 [1980]. Camera Lucida. New York: Hill and Wang. Belting, Hans. 2005. Image, Medium, Body: A New Approach to Iconology. Critical Inquiry, No. 31 (Winter): 302-319.

Bonitzer, Pascal. 1985. Décadrages: peinture et cinema. Paris: Cahiers du cinema.

Bordwell, David. 1985. Narration in the Fiction Film. Madison, Wisconsin: The University of Wisconsin Press.

Dalle Vacche, Angela. 1996. Cinema and Painting: How Art is Used in Film. Austin: University of Texas Press.

Deleuze, Gilles and Félix Guattari. 2004 [1980]. Thousand Plateaus: Capitalism and Schizophrenia. London: Continuum International Publishing Group.

Dupriez, Bernard. 1991 [1984]. A Dictionary of Literary Devices. Toronto: Toronto University Press.

Elsaesser, Thomas. 2002. Mirror, Muse, Medusa: Experiment Perilous. Senses of Cinema, Issue 18, January/February. http://archive.sensesofcinema.com/contents/01/18/perilous.html

Felleman, Susan. 2006. Art in the Cinematic Imagination. Austin: University of Texas Press.

Gaudreault, André. 1997 [1984]. Film, Narrative, Narration. The Cinema of the Lumière Brothers. In Early Cinema. Space, Frame, Narrative, ed. Thomas Elsaesser, 68-75. London: British Film Institute.

Gaudreault, André. 2009 [1988]. From Plato to Lumière. Narration and Monstration in Literature and Cinema. Toronto, Buffalo, London: University of Toronto Press.

Genette, Gérard. 1997. Paratexts: Thresholds of Interpretation. Cambridge: Cambridge University Press.

Gunning, Tom. 2000 [1990]. The Cinema of Attraction: Early Film, Its Spectator, and the Avant-Garde." In Film and Theory: An Anthology, eds. Robert Stam and Toby Miller, 229-235. Oxford: Blackwell Publishers.

Heath, Stephen. 1986. Narrative Space. In Narrative, Apparatus, Ideology, ed. Philip Rosen, 379-420. New York: Columbia University Press.

Metz, Christian. 1991 [1971]. Film Language: A Semiotics of Cinema. Chicago: University of Chicago Press.

Mitchell, W. J. T. 1994. Picture Theory. Essays on Verbal and Visual Representation. Chicago and London: University of Chigaco Press.

Mulvey, Laura. 1975. Visual Pleasure and Narrative Cinema. Screen 16.3 Autumn, 6-18.

Mulvey, Laura. 2006. Death $24 \times$ a Second. Stillness and the Moving Image. London: Reaktion Books. 
Paech, Joachim. 2000. “Artwork - Text - Medium. Steps en Route to Intermediality.” http://www.uni-konstanz.de/FuF/Philo/LitWiss/MedienWiss/ Texte/interm.html

Pethő, Ágnes. 2010. Intermediality as Metalepsis in the "Cinécriture” of Agnès Varda. Acta Universitatis Sapientiae. Film and Media Studies, Vol. 3: 69-95.

Pethő, Ágnes. 2011. Cinema and Intermediality: The Passion for the In-Between. Newcastle upon Tyne: Cambridge Scholars Publishing.

Peucker, Brigitte. 2002. Filmic Tableau Vivant, Vermeer, Intermediality and the Real. In Rites of Realism. Essays on Corporeal Cinema, ed. Ivonne Margulies, 294-315. Durham: Duke University Press.

Rajewsky, Irina O. 2005. Intermediality, Intertextuality, and Remediation: A Literary Perspective on Intermediality. Intermédialités, No 6, automne: 43-64.

Ryan, Marie-Laure. 2005. On the Theoretical Foundations of Transmedial Narratology. In Narratology beyond Literary Criticism. Mediality, Disciplinarity, ed. Jan Christoph Meister, 1-25. Berlin: Walter de Gruyter.

Ryan, Marie-Laure. 2006. Avatars of Story. Minneapolis: University of Minnesota Press.

Ryan, Marie-Laure and Marina Grishakova, eds. 2010. Intermediality and Storytelling. Berlin, New York: Walter de Gruyter.

Senkevitch, Tatiana. 2012. The Gesture of Extension. Posing (as) Las Meninas in Velázquez and Eve Sussman. Image and Narrative Vol. 13. No. 3: 17-34.

Tarnay, László. 2003. Magritte és Paradzsanov. [Magritte and Paradjanov] In Köztes képek. A filmelbeszélés színterei [Images in-between. Scenes of Filmic Narration], ed. Ágnes Pethő, 173-183. Cluj-Napoca: Scientia.

Strauven, Wanda, ed. 2006. The Cinema of Attractions Reloaded. Amsterdam: Amsterdam University Press.

Verstraten, Peter. 2009. Between Attraction and Story: Rethinking Narrativity in Cinema. In Narratology in the Age of Cross-Disciplinary Narrative Research, eds. Sandra Heinen and Roy Sommer, 154-170. Berlin, New York: Walter de Gruyter.

Vidal, Belén. 2012a. Figuring the Past. Period Film and the Mannerist Aesthetic. Amsterdm, Amsterdam University Press.

Vidal, Belén. 2012b. The Heritage Film: Nation, Genre, and Representation. New York, Chichester, West Sussex: Columbia University Press.

Wolf, Verner. 2002. Intermediality Revisited. Reflections on Word and Music Relations in the Context of a General Typology of Intermediality. In Word and Music Studies: Essays in Honor of Steven Paul Scher and on Cultural Identity and Musical Stage, eds. Steven Paul Scher, Suzanne M. Lodato, Suzanne Aspden, Walter Bernhart, 13-35. Amsterdam, New York: Rodopi. 


\section{List of Figures}

Figure 1. Marlene Dietrich in Josef von Sternberg's Shanghai Express (1932): the prolonged close up becoming one of the most often reproduced photographs of the star.
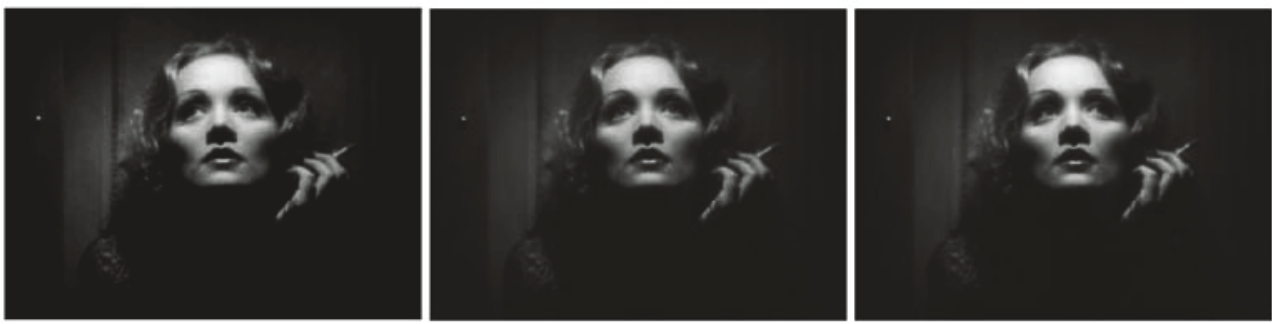

Figure 2. The trompe l'oeil tableau in The Easter Parade (1948): women framed as pictures and passing from one picture frame and form of representation to another.
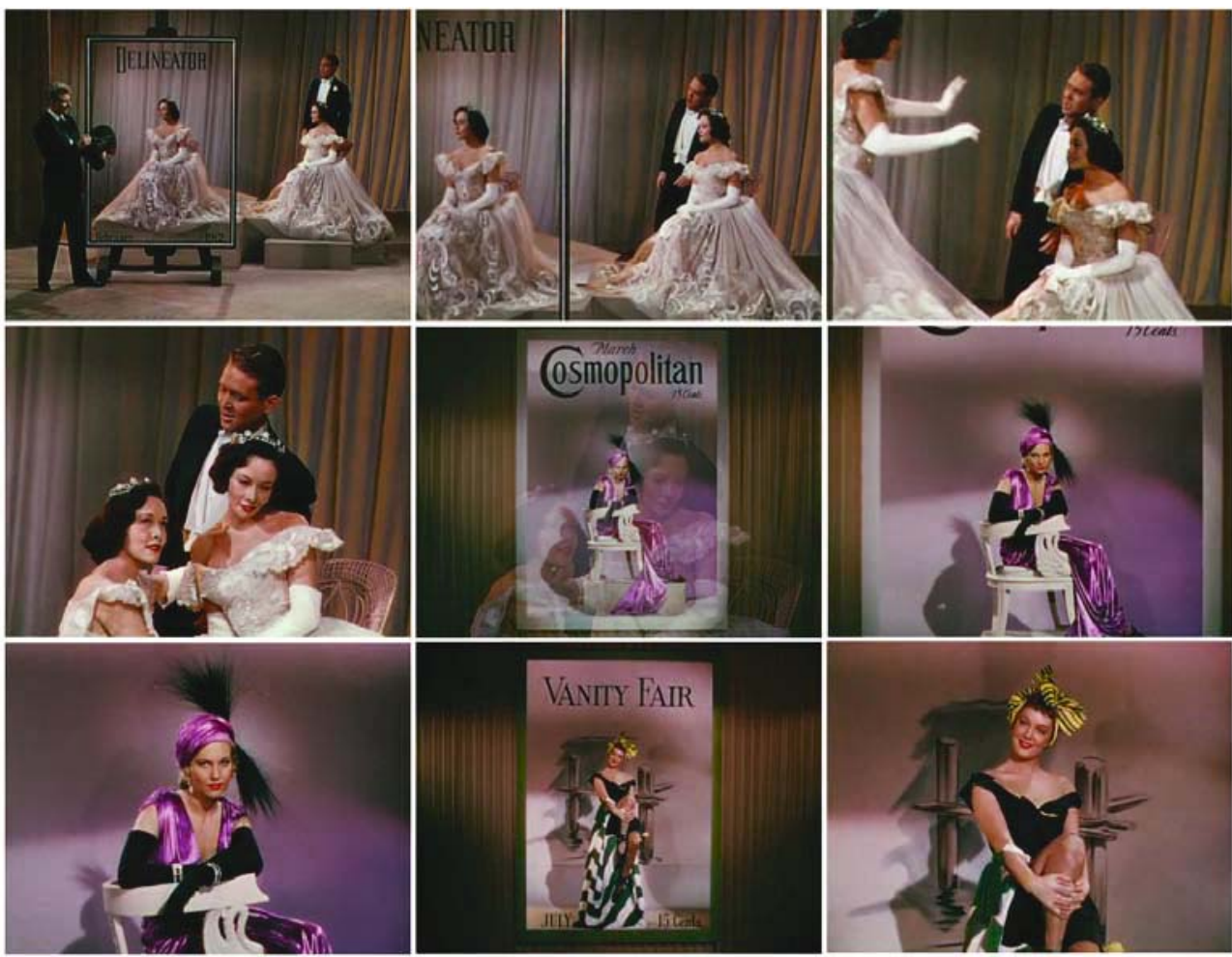
Figure 3. Hans Holbein The Ambassadors (1533) with the anamorphosis of a skull in the foreground.
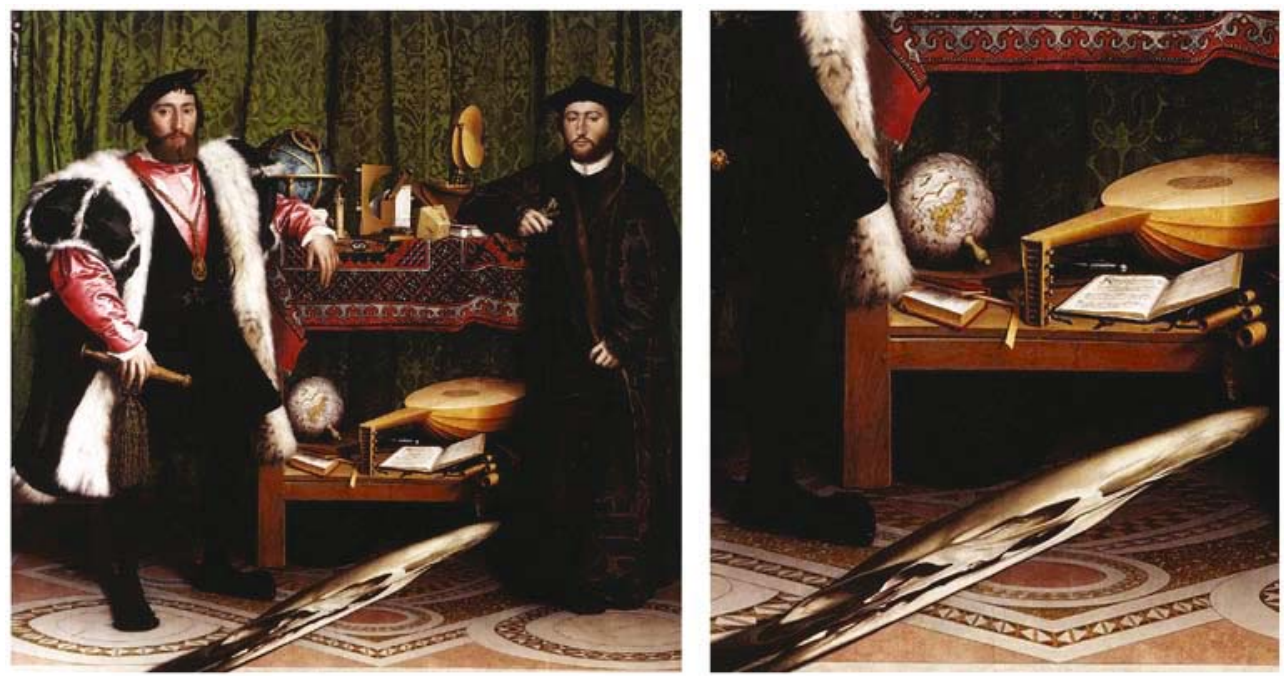

Figure 4. Hitchcock's Suspicion (1941): the disruptive effect of a cubist painting, and the invasion of the cinematic image with abstract shapes and lines.

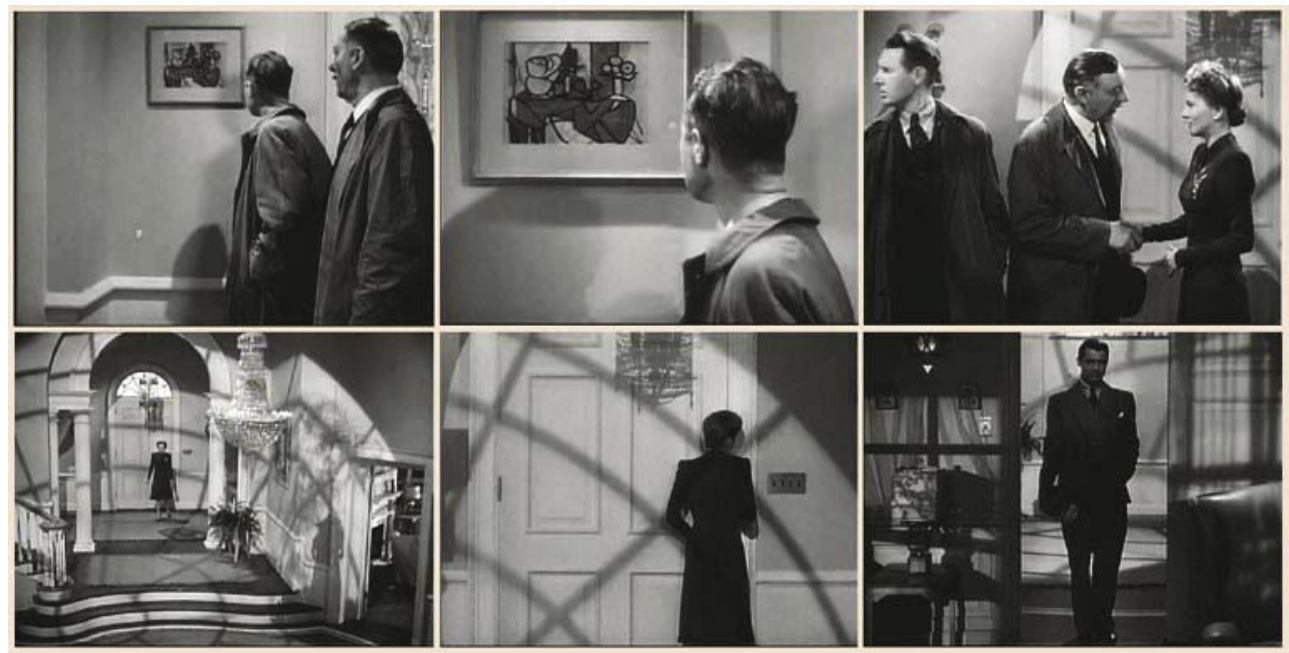


Figure 5. The painting/woman as an enigma in Jacques Tourneur's Experiment Perilous (1944), Otto Preminger's Laura (1944), and Fritz Lang's The Woman in the Window (1944)
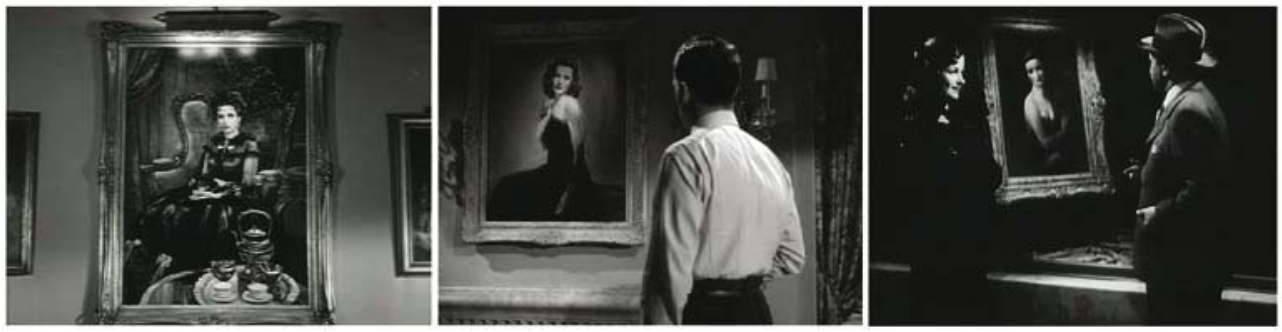

Figure 6. Laurent de Bartillat The Vanishing Point (2007): detecting the story in the painting.
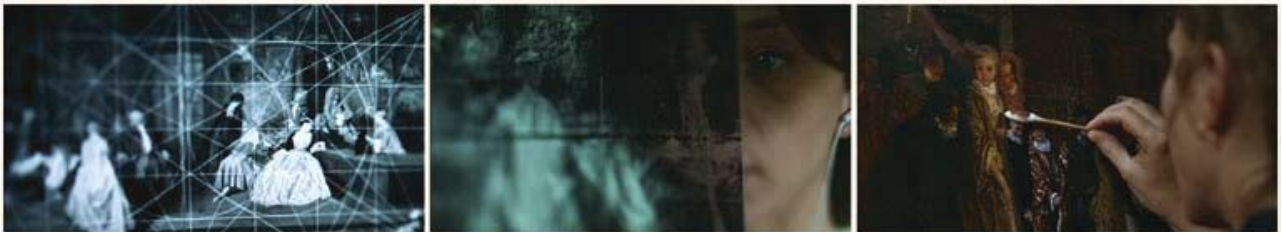

Figure 7. Narrative as an elaborate caption to a single painting: Girl with a Pearl Earring (Peter Webber, 2003), Volavérunt: The Naked Maja (Bigas Luna, 1999), Peter Greenaway: Nightwatching (2007).
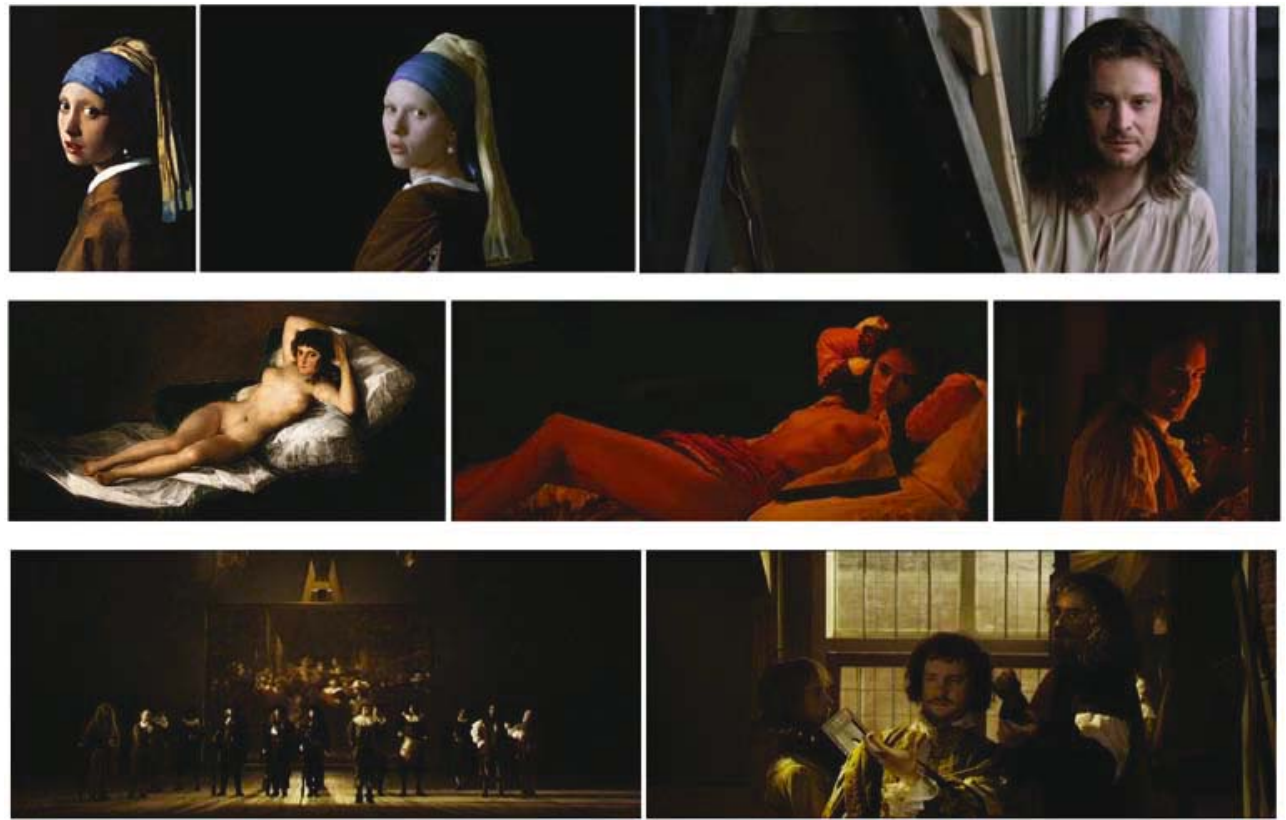
Figure 8. Stories constructed as "psycho-ekphrasis" around a fetish tableau in historical biopics: Stephen Frears: The Queen (2006), Shekhar Kapur: Elizabeth (1998)
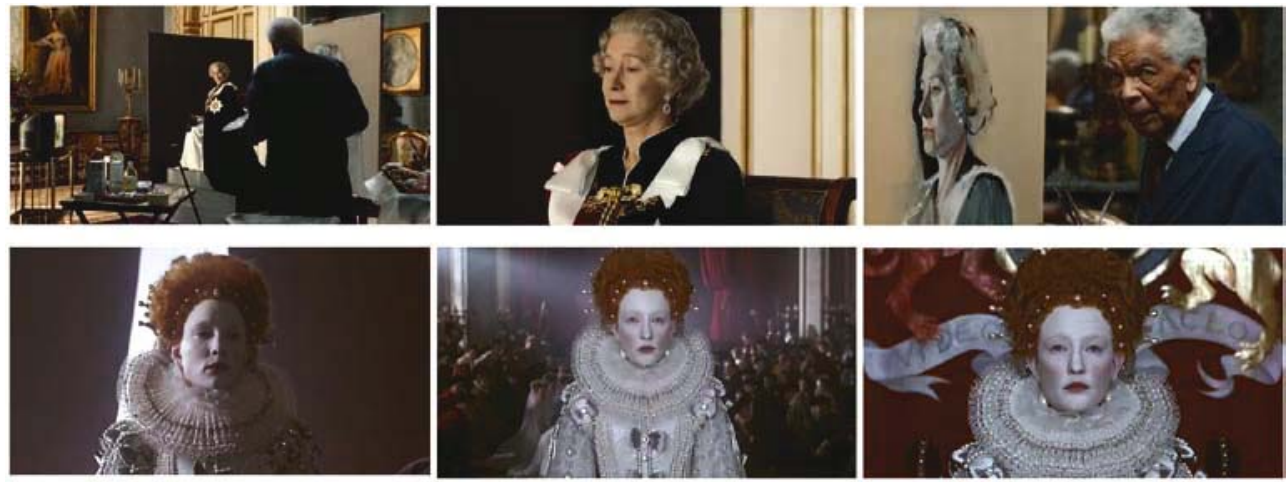

Figure 9. Paintings as paratexts and pre-texts: Bertolucci's The Last Tango in Paris (1972)
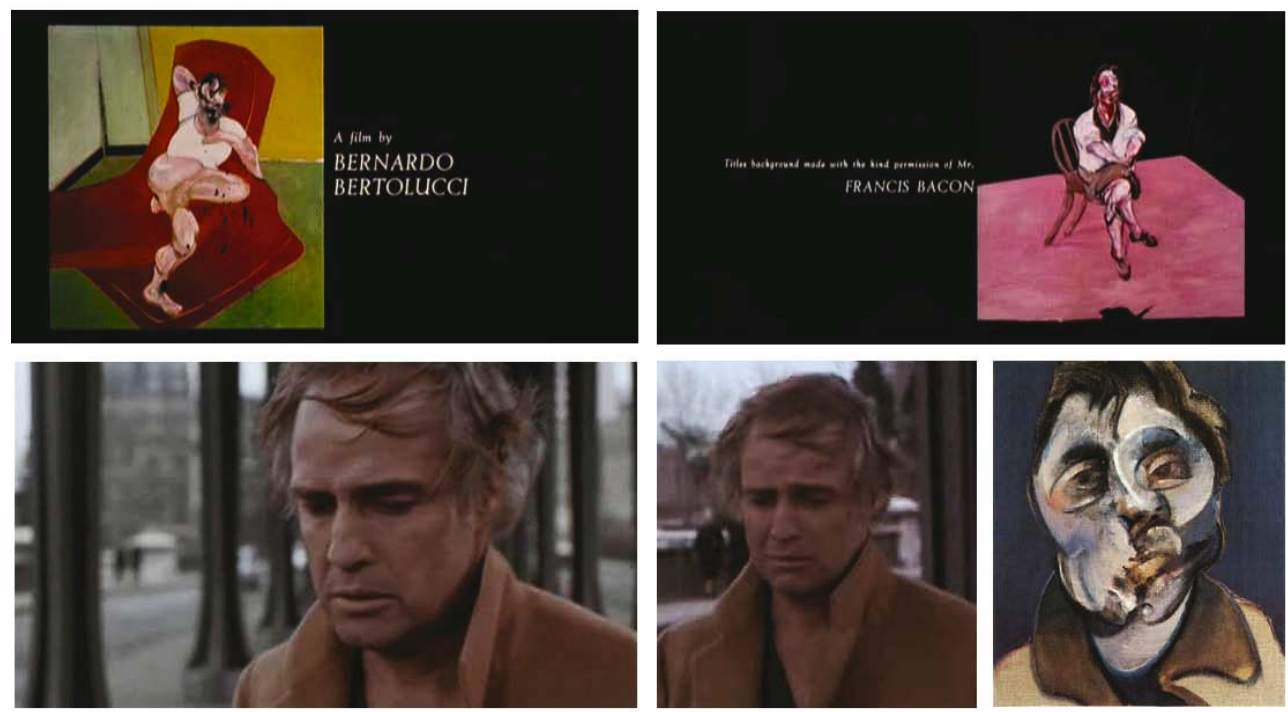
Figure 10. Eve Sussman: 89 Seconds at Alcázar (2004)
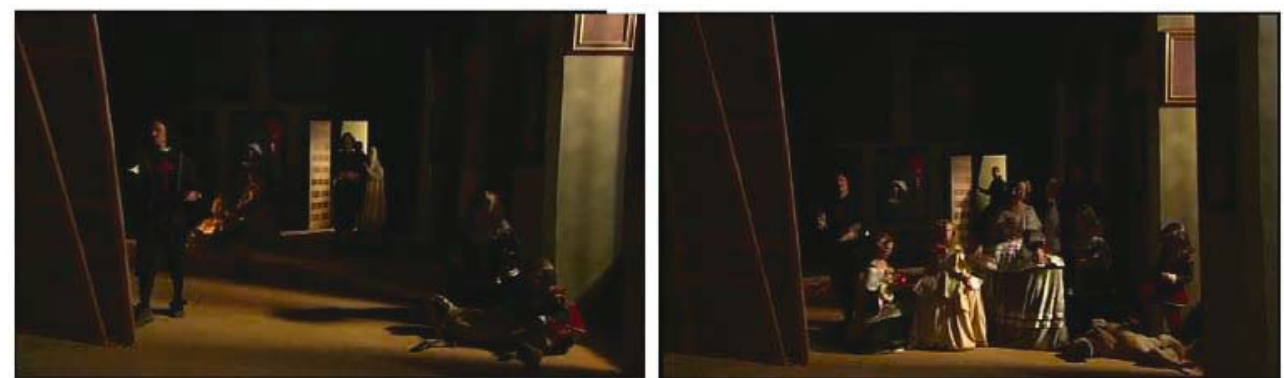

Figure 11. Marcell Iványi: The Wind (1966)
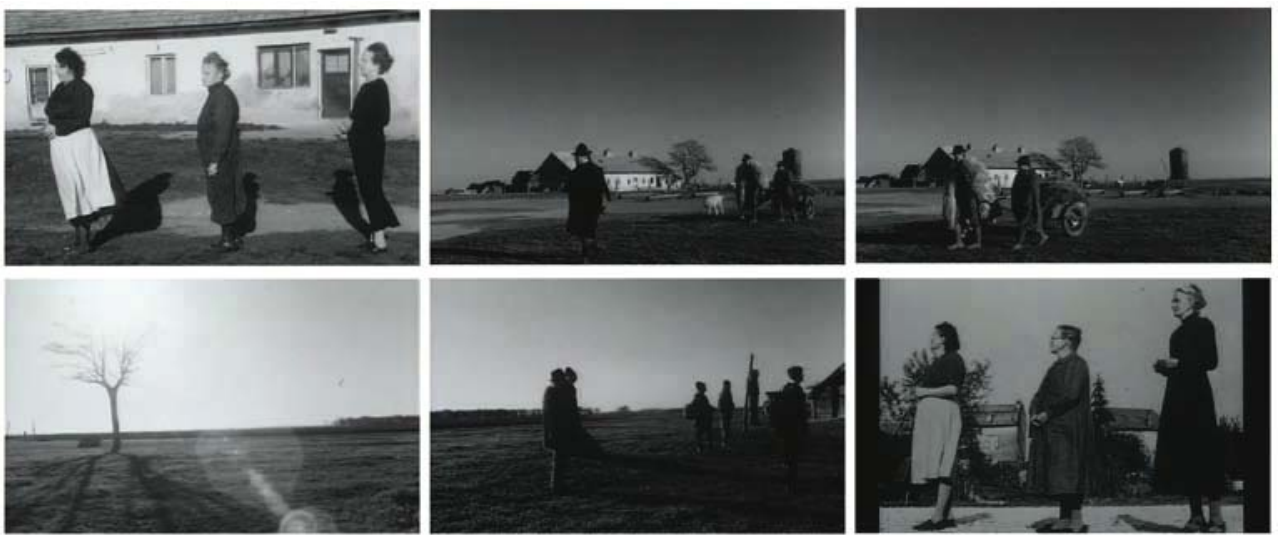

Figure 12. Painterly stylization as metalepsis: Love is the Devil (John Maybury, 1998)
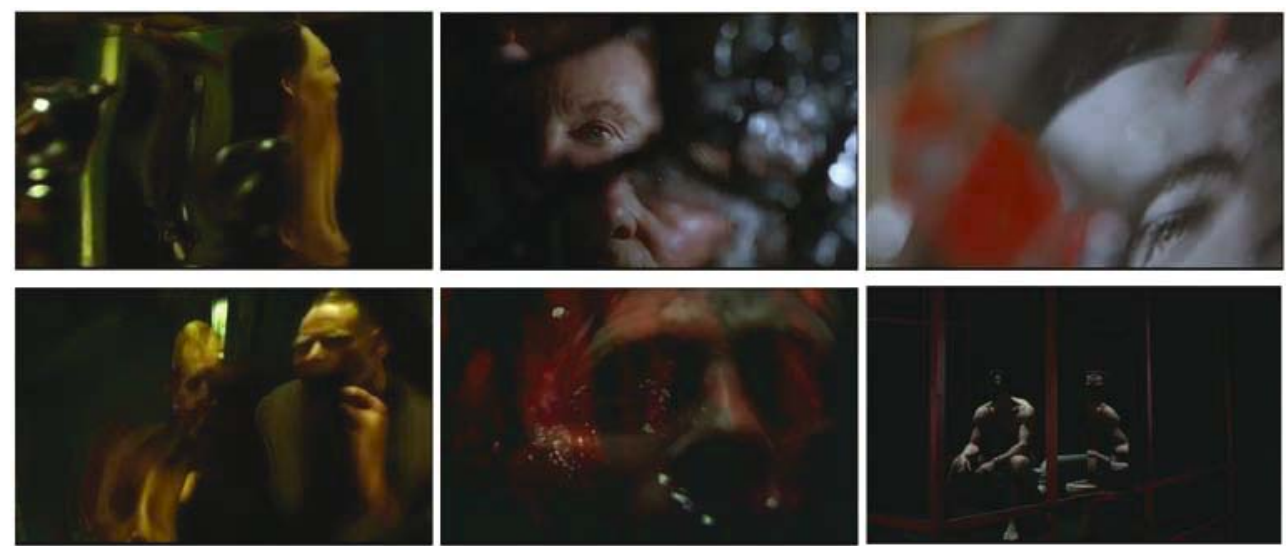
Figure 13. The tableau vivant as hypotyposis: Albert Lewin's The Private Affairs of Bel Ami (1947), Woody Allen's Midnight in Paris (2011).
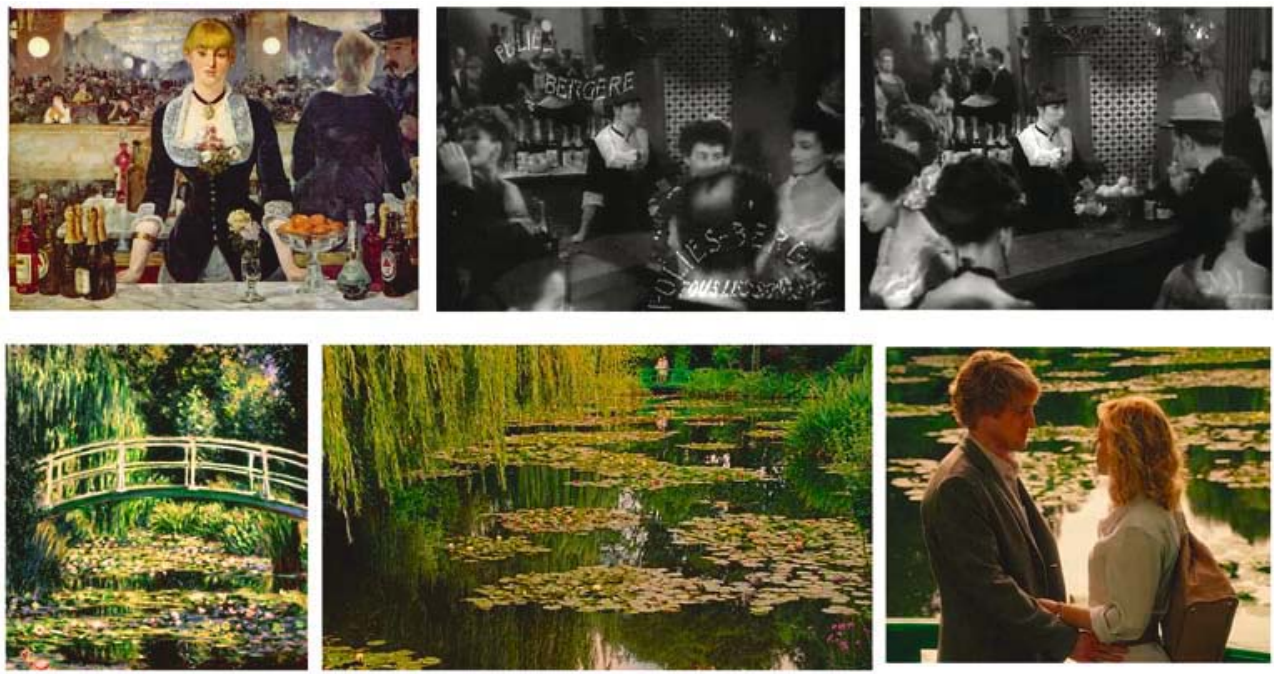

Figure 14. The tableau vivant as a palimpsest of narrative modes and narratives in Lech Majewski's The Mill and the Cross (2011)
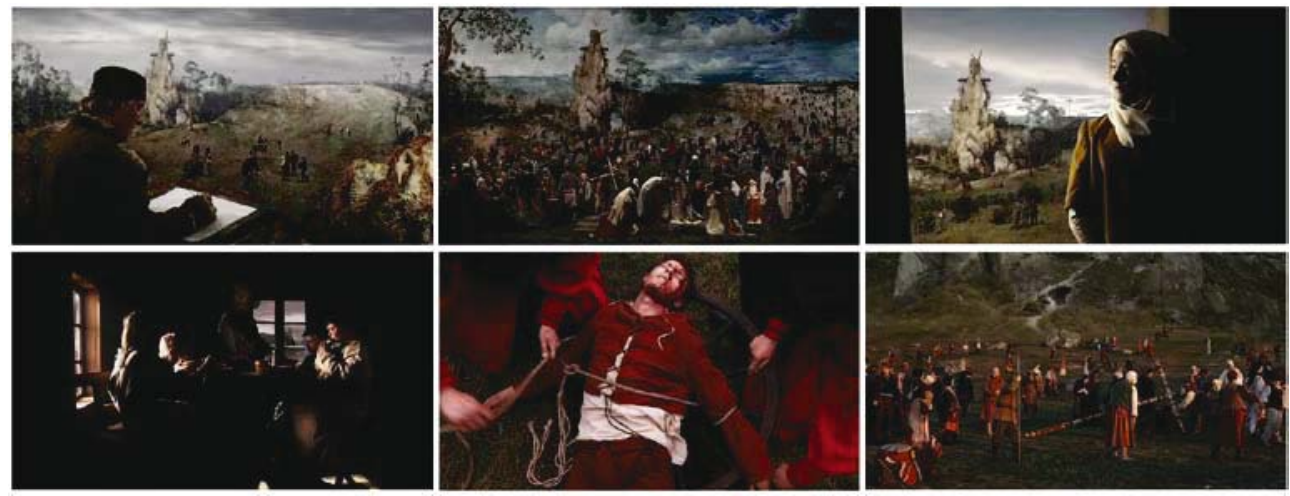